\title{
Social Skills Scale
}

National Cancer Institute

\section{Source}

National Cancer Institute. Social Skills Scale. NCI Thesaurus. Code C121296.

A rating scale included in the Behavior Assessment System for Children that measures the skills necessary for the subject to interact successfully with peers and adults in home, school, and community settings. 